\title{
Medicago truncatula Oleanolic-Derived Saponins Are Correlated with Caterpillar Deterrence
}

\author{
Fanping Cai ${ }^{1}$ - Bonnie S. Watson ${ }^{2} \cdot$ David Meek $^{3} \cdot$ David V. Huhman ${ }^{2} \cdot$ \\ Daniel J. Wherritt ${ }^{4}$ - Cecile Ben ${ }^{5} \cdot$ Laurent Gentzbittel $^{5}$ • Brian T. Driscoll ${ }^{3}$. \\ Lloyd W. Sumner ${ }^{2,6}$. Jacqueline C. Bede ${ }^{1}$ (D)
}

\begin{abstract}
Plant resistance mechanisms to insect herbivory can potentially be bred into crops as an important strategy for integrated pest management. Medicago truncatula ecotypes inoculated with the rhizobium Ensifer medicae (Sinorhizobium medica) WSM419 were screened for resistance to herbivory by caterpillars of the beet armyworm, Spodoptera exigua, through leaf and whole plant choice studies; TN1.11 and F83005.5 are identified as the least and most deterrent ecotypes, respectively. In response to caterpillar herbivory, both ecotypes mount a robust burst of plant defensive jasmonate phytohormones. Restriction of caterpillars to either of these ecotypes does not adversely affect pest performance.

Electronic supplementary material The online version of this article (doi:10.1007/s10886-017-0863-7) contains supplementary material, which is available to authorized users.

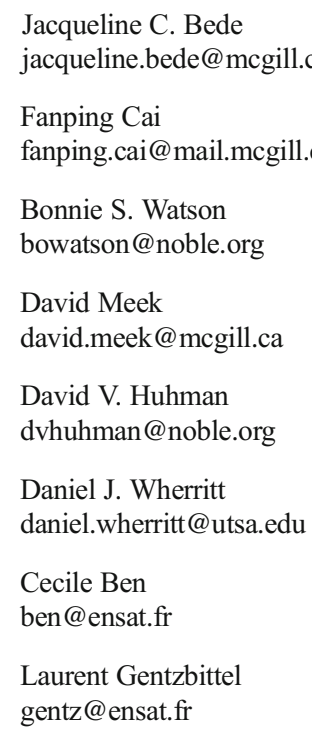

This argues for an antixenosis (deterrence) resistance mechanism associated with the F83005.5 ecotype. Unbiased metabolomic profiling identified strong ecotype-specific differences in metabolite profile, particularly in the content of oleanolic-derived saponins that may act as antifeedants. Compared to the more susceptible ecotype, F83005.5 has higher levels of oleanolic-type zanhic acid- and medicagenic acid-derived compounds. Together, these data support saponin-mediated deterrence as a resistance mechanism of the F83005.5 ecotype and implicates these compounds as potential antifeedants that could be used in agricultural sustainable pest management strategies.

Brian T. Driscoll

brian.driscoll@mcgill.ca

Lloyd W. Sumner

sumnerlw@missouri.edu

1 Department of Plant Science, McGill University, 21,111 Lakeshore, Ste-Anne-de-Bellevue, QC H9X 3V9, Canada

2 The Samuel Roberts Noble Foundation, Ardmore, OK 73401, USA

3 Natural Resource Sciences, McGill University, Ste-Anne-de-Bellevue, QC H9X 3V9, Canada

4 Department of Chemistry, University of Texas at San Antonio, San Antonio, TX 78249, USA

5 EcoLab, Université de Toulouse, Centre National de Recherche Scientifique, Institute National Polytechnique de Toulouse, Université Paul Sabatier, Toulouse, France

6 Present address: Department of Biochemistry, University of Missouri, Columbia, MO 65211, USA 
Keywords Antifeedant - Antixenosis - Caterpillar herbivory · Deterrence $\cdot$ Medicago truncatula $\cdot$ Plant-insect interactions . Plant resistance $\cdot$ Spodoptera exigua

$\begin{array}{ll}\text { Abbreviations } & \\ \text { ANOVA } & \text { Analysis of variance } \\ \text { Api } & \text { Apiofuranose } \\ \text { Ara } & \text { Arabinose } \\ \text { Dhex } & \text { Deoxyhexose } \\ \text { Glc } & \text { Glucose } \\ \text { GlcA } & \text { Galacuronic acid } \\ \text { Hex } & \text { Hexose } \\ \text { HexA } & \text { Uronic acid } \\ \text { HPLC-MS/MS } & \text { High performance liquid chromatogra- } \\ & \text { phy-tandem mass spectroscopy } \\ \text { JA } & \text { Jasmonic acid } \\ \text { JA-Ile } & (+)-7-i s o-\text { jasmonyl-L-isoleucine } \\ \text { LD } & \text { Least deterrent } \\ \text { MD } & \text { Most deterrent } \\ \text { NMR } & \text { Nuclear magnetic resonance } \\ \text { OPDA } & \text { cis-(+)-12-Oxo-phytodienoic acid } \\ \text { Pen } & \text { Pentose } \\ \text { PCA } & \text { Principal component analysis } \\ \text { Rha } & \text { Rhamnose } \\ \text { UPLC-qTOF-MS } & \text { Ultrahigh performance liquid } \\ & \text { chromatography-quantitative time-of- } \\ & \text { flight-mass spectroscopy } \\ \text { Xyl } & \text { Xylose }\end{array}$

\section{Introduction}

Globally, $\sim 15 \%$ of agricultural crops are lost annually to insect infestation and is predicted to increase under changing climactic conditions (Maxmen 2013). Through a better understanding of plant resistance, molecular or selective breeding practices may lead to an enhancement of endogenous defenses allowing for better crop protection. Plant resistance to insect herbivory can be broadly characterized as antixenosis, antibiosis or tolerance that involve mechanisms to avoid, reduce or recover from damage by insect pests (Smith and Clement 2012). Tolerance refers to the ability of a plant to cope with a certain level of insect herbivory (Trumble et al. 1993). In some cases, this may even result in stimulating growth; overcompensatory growth (Scholes et al. 2013). Plant defenses may form part of antibiosis or antixenosis resistance. Plant specialized (secondary) metabolites may act directly on the herbivore to negatively affect growth, development and fecundity or survival; all of which may result in a substantial decline in pest populations (Mithöfer and Boland 2012). This resistance is termed antibiosis. Antixenosis or deterrence occurs when the insect is repelled by or not attracted to its potential host plant (Smith and Clement 2012). Antifeedants that affect the insect behaviour, thereby reducing feeding, contribute to antixenosis resistance mechanisms (Isman 2002; Koul 2008).

In Western Australia, North Africa and Mediterranean countries, the barrel medic, Medicago truncatula Gaert., is an annual forage and green manure crop (Tivoli et al. 2006). Medicago truncatula Jemalong A17 (A17) has become a model to investigate temperate legume-rhizobial and other biotic interactions (Rose 2008; Tang et al. 2014; Young and Udvardi 2009). The strong colinearity between the genome of this plant and other legumes has allowed information learned from this tractable model to be applied to other temperate legumes (Choi et al. 2004; Young et al. 2005). In this study, we analyze the resistance of six M. truncatula ecotypes (A17, A20, DZA045.5, DZA315.16, F83005.5 and TN1.11), that were isolated from different geographical regions and environmental conditions, to caterpillar herbivory (Table 1) (Gentzbittel et al. 2015; Lazrek et al. 2009).

Previous studies have compared M. truncatula ecotype responses to environmental, pathogen and insect stresses (Gao et al. 2008; Rubiales et al. 2015; Stewart et al. 2009; Zahaf et al. 2012) (Table 1). Pea aphid, Acyrthosiphon pisum, showed a preference for M. truncatula A17 over the Jester cultivar in a choice study (Gao et al. 2008). However, when compared to ecotypes A20 and DZA315.16, A17 showed higher resistance against pea aphid (Guo et al. 2012; Stewart et al. 2009). Therefore, M. truncatula has a range of resistance, both in level and type (antibiosis and antixenosis), against $A$. pisum. Further genetic studies identified the QTL RAP1 as important in pea aphid resistance (Stewart et al. 2009). Most studies comparing ecotype resistance to insect herbivory have focused on phloem-feeding aphids rather than chewing herbivores, such as caterpillars. In this study, we subject $M$. trunctula ecotypes to herbivory by caterpillars of the economically important pest, the beet armyworm, Spodoptera exigua Hübner (Greenberg et al. 2001). These caterpillars are generalists able to feed and cause significant damage to diverse agricultural crops.

In M. truncatula, the principal foliar defensive compounds are pentacyclic triterpenoid saponins that may lead to prolonged development, reduced survivorship and lower fitness of diverse insect herbivores, from aphids to caterpillars (Adel et al. 2000; Agrell et al. 2003; Da Silva et al. 2012; De Geyter et al. 2007; Gholami et al. 2014; Goławska et al. 2012; Nozzolillo et al. 1997; Tava and Odoardi 1996). In Medicago species, these glycosylated compounds can be broadly grouped as soyasapogenol-, gypsogenic acid-, medicagenic acid- or zhanhic acid-derived depending on the nature of the aglycone core (Gholami et al. 2014; Huhman and Sumner 2002; Huhman et al. 2005; Kapusta et al. 2005). At $\beta$-amyrin, the saponin biosynthesis pathway bifurcates into the 
Table 1 Medicago truncatula ecotypes used in this study (www1.montpellier.inra.fr/BRC-MTR/accueil.php; www.medicagohapmap.org)

\begin{tabular}{|c|c|c|c|}
\hline Ecotype & $\begin{array}{l}\text { Country of origin; Altitude; Latitude; } \\
\text { Longitude (if known) }\end{array}$ & Notes & Reference \\
\hline \multirow[t]{4}{*}{ Jemalong A17 } & \multirow[t]{4}{*}{ Derived from Jemalong Australian cultivar } & - Reference genome & $\begin{array}{l}\text { (Tang et al. 2014; Young and Udvardi } \\
\text { 2009) }\end{array}$ \\
\hline & & $\begin{array}{l}\text { - Partial resistance to Aphanomyces euteiches } \\
\text { and Macrophomina phaseolina }\end{array}$ & (Djébali et al. 2009; Gaige et al. 2012) \\
\hline & & $\begin{array}{l}\text { - Resistance to Verticillium alfalfae, more } \\
\text { susceptible to Verticillium non-alfalfae }\end{array}$ & $\begin{array}{l}\text { (Ben et al. 2013a; Ben et al. 2013b; } \\
\text { Negahi et al. 2013) }\end{array}$ \\
\hline & & $\begin{array}{l}\text { - Partial resistance to pea aphid, compared to } \\
\text { A20 and DZA315.16 but more susceptible } \\
\text { than Jester }\end{array}$ & (Guo et al. 2012, Stewart et al. 2009) \\
\hline Jemalong A20 & Derived from Jemalong Australian cultivar & & \\
\hline DZA045.5 & Annaba, Algeria, $100 \mathrm{~m}, 36.9^{\circ} \mathrm{N}, 7.7^{\circ} \mathrm{E}$ & & \\
\hline DZA315.16 & $\begin{array}{l}\text { Ain El Hadjar, Algeria, } 1070 \mathrm{~m}, 34.7^{\circ} \mathrm{N}, \\
0.16^{\circ} \mathrm{E} .\end{array}$ & & \\
\hline TN1.11 & Tunisia & $\begin{array}{l}\text { - Isolated from an arid, saline soil } \\
\text { - Tolerance to saline conditions } \\
\text { - Susceptibility to } \mathrm{Cd}^{2+} \text { toxicity }\end{array}$ & $\begin{array}{l}\text { (Zahaf et al. 2012) } \\
\text { (Rahoui et al. 2014; Raho }\end{array}$ \\
\hline F83005.5 & Salenes, France, $261 \mathrm{~m} ; 43.5^{\circ} \mathrm{N} ; 6.23^{\circ} \mathrm{E}$ & $\begin{array}{l}\text { - Partial resistance to Verticillium albo-atrum } \\
\text { but susceptible to V. alfalfae } \\
\text { - More susceptible to Aphanomyces euteiches } \\
\text { compared to A17 } \\
\text { - Resistance to Ralstonia solanacearum } \\
\text { GMI1000 }\end{array}$ & $\begin{array}{l}\text { (Ben et al. 2013a; Ben et al. 2013b; } \\
\text { Djébali et al. 2009; Negahi et al. } \\
\text { 2013) }\end{array}$ \\
\hline
\end{tabular}

oleanolic- (gypsogenic acid, medicagenic acid or zhanhic acid) or soyasapogenol-derived compounds.

Their biological activities are as diverse as the compounds themselves, though some generalizations may be made. These amphipathic compounds readily form micelles that may lead to cell permeabilization or bind hydrophobic compounds, lowering their availability (De Geyter et al. 2007; Moses et al. 2014). For example, though still contentious, the haemolytic property of oleanolic-derived saponins may result from the interactions with plasma membrane cholesterol, forming pores and leading to permeabilization (Podolak et al. 2010). In insect cell culture, saponins from soapbark tree, Quillaja saponaria, formed pores in the membrane resulting in permeabilization, suggesting a direct cytotoxic role (De Geyter et al. 2012). Through micelle formation, saponins may lower the nutrients available to the insect and/or disrupt growth (De Geyter et al. 2007; Moses et al. 2014). By binding to phytosterols that are necessary diet-derived precursors of the molting hormone ecdysone, saponins may disrupt insect growth. Saponins may also directly interact with ecdysteroid receptors. Therefore, phytosaponins are thought to protect the plant against insect herbivory by acting as antifeedants and/or growth inhibitors.

Medicago saponins have strong insecticidal properties. An inverse relationship was found between the saponin content of different alfalfa cultivars and aphid infestation (Goławska et al. 2012). An alfalfa saponin extract adversely affected caterpillar growth of the European corn borer, Ostrinia nubialis, and caterpillar survival of the European grape moth, Lobesia botrana, and the summer fruit tortix, Adoxophyes orana (Nozzolillo et al. 1997; Tava and Odoardi 1996). Egyptian cotton leafworm, Spodoptera littoralis, caterpillars fed artificial diet laced with saponin extract from alfalfa, showed high larval mortality, increased developmental time and lower pupal mass and emergence rates (Adel and Sammour 2012); a decline in fitness was observed with female moths laying $60 \%$ less eggs that had a lower hatch rate. These effects were not related with the efficiency of food conversion, but reflected longer food retention in the gut (Adel et al. 2000). The most potent of these effects are attributed to medicagenic-type saponins with soyasapogenolderivatives showing minimal activity. Alfalfa medicagenic acid-derivatives are toxic to the pea aphid, Acyrthosiphon pisum, potato leafhopper, Empoasca fabea and rice weevil, Sitophilus oryzae adults (Da Silva et al. 2012; Goławska 2007; Goławska et al. 2012; Horber et al. 1974).

In addition to direct effects, saponins often act as feeding deterrents, negatively affecting feeding behavior supporting an antixenosis resistance mechanism (Isman 2002; Koul 2008). In most cases, antifeedants act by either stimulating deterrent sensory cells or interfering with phagostimulatory signals. This insect behavioural rejection of the plant is often guided by broad range deterrent chemosensilla rather than recognition of potential toxic compounds (Koul 2008). 
Oleanolic-derived saponins, with zanhic acid or medicagenic acid aglycones, negatively affected pea aphid probing behaviour (Goławska 2007). Rice weevil, Sitophilus oryzae, feeding was not affected by soyasaponin B but, in contrast, these weevils were strongly deterred by the ketone derivative of this compound at carbon 22, dehydrosoyasaponin B (Taylor et al. 2004). Larval Colorado potato beetle, Leptinotarsa decemlineata, feeding was also negatively affected in a dose-dependent manner by a crude saponin extract from alfalfa shoots (Szczepanik et al. 2001). In choice studies, Spodoptera littoralis caterpillars preferentially feed from undamaged alfalfa rather than wounded alfalfa that had higher total levels of soyasaponin-based and medicagenin-based saponins, but not total flavonoids (Agrell et al. 2003); when restricted to these plants, an effect on caterpillar development was not observed. Collectively, these studies imply that Medicago-derived saponins act as feeding deterrents and/or toxic compounds but, generally, do not seem to interfere directly with insect development.

In this study, six M. truncatula ecotypes (A17, A20, DZA045.5, DZA315.16, F83005.5 and TN1.11) were compared for resistance against 4th instar $S$. exigua caterpillar herbivory. An in vitro leaf choice study was conducted to rank the $M$. truncatula ecotypes. From this, the two most resistant and two most susceptible cultivars were selected and through whole plant choice studies, the more herbivore resistant and more susceptible ecotypes were identified. Caterpillar performance on the more resistant and more susceptible ecotypes was compared in terms of survivorship, developmental progress and pupal biomass, since it is closely related to fecundity (Greenberg et al. 2001). Constitutive and induced defenses in response to caterpillar herbivory were compared in these two ecotypes. Defense-related phytohormone levels were analyzed by high performance liquid chromatography-tandem mass spectroscopy. Unbiased metabolomics, focusing on saponins, the principal defense compounds in Medicago, were measured by ultrahigh performance liquid chromatographyquadruple time-of-flight - mass spectroscopy.

\section{Methods and Materials}

Chemicals All chemicals were obtained from Sigma Aldrich Co. unless otherwise noted. All solvents used in the analytical analysis (hormones, saponins) were high performance liquid chromatography (HPLC)-grade.

Plant Cultivation Seeds of $M$. truncatula Gaertn. ecotypes (A17, F83005.5, DZA315.16, DZA045.5, A20, TN1.11), obtained from inbred lines derived from a natural diversity collection available through the INRA Biological Resource Centre (INRA BRC-MTR, Montpellier) (Table 1), were scarified in $98 \%$ sulfuric acid for $15 \mathrm{~min}$, rinsed five times in sterile distilled water and placed in a Petri dish on moist filter paper (Garcia et al. 2006). Plates were placed at $4{ }^{\circ} \mathrm{C}$ for 2 days in the dark to break dormancy and then at $22^{\circ} \mathrm{C}$ in the light. Germinated seeds were transferred to Farfard (PV20 Agro Mix) potting mixture that had been pasteurized at $80{ }^{\circ} \mathrm{C}$ for $2 \mathrm{hr}$ and placed in a phytorium cabinet (16:8 light-to-dark cycle, light intensity $260 \mu \mathrm{E} \mathrm{m}^{-2} \mathrm{~s}^{-1}, 22{ }^{\circ} \mathrm{C}$ ). Plants were bottom-watered 3 times per week with dilute 20-20-20 NPK fertilizer $(0.15 \mathrm{~g}$ per liter) for the first two weeks. To simulate natural conditions at two weeks, plants are inoculated with the rhizobium, Ensifer medicae (Sinorhizobium medica) WSM419 and then fertilized 3 times per week with sterile nitrogen-free fertilizer $\left(\mathrm{MgSO}_{4} \cdot 7 \mathrm{H}_{2} \mathrm{O}, 0.31 \mathrm{mg} / 1 ; \mathrm{KH}_{2} \mathrm{PO}_{4}\right.$, $0.21 \mathrm{mg} / \mathrm{l} ; \mathrm{K}_{2} \mathrm{SO}_{4}, 0.44 \mathrm{mg} / \mathrm{l}$; FeEDTA, $0.06 \mathrm{mg} / \mathrm{l} ; \mathrm{CaSO}_{4}$, $0.05 \mathrm{mg} / \mathrm{l} ; \mathrm{H}_{3} \mathrm{BO}_{4}, 0.116 \mathrm{mg} / \mathrm{l} ; \mathrm{Na}_{2} \mathrm{MoO}_{4} \cdot 2 \mathrm{H}_{2} 0,0.0045 \mathrm{mg} /$ 1; $\mathrm{ZnSO}_{4} \cdot 7 \mathrm{H}_{2} \mathrm{O}, 0.134 \mathrm{mg} / 1 ; \mathrm{MnSO}_{4} \cdot \mathrm{H}_{2} \mathrm{O}, 0.01 \mathrm{mg} / \mathrm{l}$; $\left.\mathrm{CoSO}_{4} \cdot 7 \mathrm{H}_{2} \mathrm{O}, 0.03 \mathrm{mg} / 1 ; \mathrm{CaSO}_{4} \cdot 5 \mathrm{H}_{2} \mathrm{O}, 0.03 \mathrm{mg} / \mathrm{l}\right)$.

Rhizobium Culture and Plant Inoculation Ensifer medicae (Sinorhizobium medicae) WSM419 (gift from Drs. J. Terpolilli and J. Howieson, Murdoch University; Terpolili et al. 2008) was cultured on TYE plates $\left(\mathrm{K}_{2} \mathrm{HPO}_{4} 0.5 \mathrm{~g} / \mathrm{l}\right.$; $\mathrm{MgSO}_{4} \cdot 7 \mathrm{H}_{2} \mathrm{O}$ g/l; $\mathrm{NaCl} 0.1 \mathrm{~g} / \mathrm{l} ;$ Mannitol $10 \mathrm{~g} / \mathrm{l}$; Yeast extract $1.0 \mathrm{~g} / 1 ; 1.5 \%$ agar). Colonies were picked as soon as they were visible (approx. $3-5$ days at $30^{\circ} \mathrm{C}$ ) and cultured in liquid TYE medium. When cultures reached an $\mathrm{OD}_{600 \mathrm{~nm}}=0.7$ to $0.8,3 \mathrm{ml}$ was used to inoculate 2-week-old plants. After the experiment, roots were checked to verify nodule infection.

Insect Maintenance Spodoptera exigua (Hübner) (Lepidoptera: Noctuidae) caterpillars were reared on a wheat germ-based artificial diet (BioServ) in growth cabinets at $28.5^{\circ} \mathrm{C}, 28-40 \%$ relative humidity and a $16: 8$ light-to-dark cycle. Pupae were transferred into a glass bottle for moth eclosion and mating. Paper towels were provided as an egg laying substrate. Eggs were moved to a new container to maintain the colony.

In Vitro Choice Test Feeding preference studies were conducted by dual-choice tests allowing caterpillars to feed on leaves from M. truncatula ecotypes. Three preweighed, newly mature trifoliate leaves from two different 6-week-old M. truncatula ecotypes (6 leaves in total) were placed in a Petri dish equidistant from the centre, with each ecotype being located in different halves of the dish. After being starved for one hour, one 4th instar S. exigua caterpillar was placed in the center of the dish and allowed to feed for $9 \mathrm{hr}$ from $10 \mathrm{pm}$ to $7 \mathrm{am}$ in the dark. Any experiments where leaves were completely eaten were discarded. To ensure random feeding, controls comparing herbivory on two sets of leaves from the same ecotype (random feeding control) were performed. Leaves were collected and dried in a paper bag in an oven at $40{ }^{\circ} \mathrm{C}$ until they reached a consistent dry weight. In addition to 
these leaves, a set of fresh leaves from each ecotype were also weighed fresh and dried to determine the fresh weight - to dry weight conversion factor. The consumed fresh weight leaf biomass was calculated using this conversion factor. The experiment was repeated three times with at least 8 biological replicates per experimental replicate $(n=24)$. Paired Student's t-test was used to compare biomass loss (Supplemental Table 1A).

Whole plant Choice Test Based on the leaf choice assay, the two more caterpillar-resistant (A17 and F83005.5) and the two more caterpillar-susceptible (DZA315.16 and TN1.11) ecotypes were used in the whole plant choice experiment. Caterpillars were given choices between two $M$. truncatula ecotypes grown in the same 6 in. pot; there was little difference in the mean final biomass of the different ecotypes as determined from the fresh weight of undamaged control plants (3.8-6 g, data not shown). Six - week - old plants were enclosed using a clear plastic 21 bottle. Three 2 nd instar caterpillars were placed on the soil between the plants and allowed to feed until pupation. To ensure random feeding, a control was performed comparing herbivory on two plants of the same ecotype (random feeding control). When the insects pupated, foliar plant tissues were removed and dried in a paper bag in an oven at $40{ }^{\circ} \mathrm{C}$ until they reach a consistent dry weight.

Plants from each ecotype without caterpillars were used to determine the fresh weight - to - dry weight conversion to estimate the plant starting weight. The experiment was repeated twice with 5 biological replicates $(n=10)$. Paired Student's t-test was used to compare biomass loss (Supplemental Table 1B).

Insect Development and Performance Three 2 nd instar S. exigua caterpillars were restricted on 6-week-old plants of either the more resistant F83005.5 or more susceptible TN1.11 ecotypes. Caterpillar developmental stage was assessed each two or three days until pupation. The experiment was repeated three times with 24 caterpillars per ecotype per temporal replication ( 3 caterpillars on 8 plants, 2 ecotypes, 3 temporal replicates, total $n=144$ ). Percent survivorship and caterpillar developmental instar were compared by Pearson's Chi-Square analysis (Supplemental Table IIA). In a parallel experiment, three 2nd instar caterpillars were allowed to feed on plants until pupation. Pupae were collected and dried at $70{ }^{\circ} \mathrm{C}$ until a constant dry weight was reached. The experiment was repeated three times ( 3 caterpillars on 8 plants, 2 ecotypes, 3 temporal replicates, total $n=144$ ). Pupal dry weight was compared by Student's t-test (Supplemental Table IIA).

Constitutive and Induced Plant Defense Responses Based on the whole plant choice assay, the constitutive and induced defenses of the more resistant F83005.5 and more susceptible
TN1.11 ecotypes were compared. Six-week-old plants were enclosed in a clear plastic bottle (2 1). Half of these plants were treated with three 2 nd instar $S$. exigua caterpillar that were allowed to feed until pupation ( $\sim 2$ weeks). The other half of the plants were not subject to insect herbivory. To measure constitutive responses, all fully open leaves were removed from untreated control plants and immediately frozen in liquid nitrogen $\left(\mathrm{N}_{2}\right)$. For the induced responses, damaged leaves were removed from caterpillar-infested plants and immediately frozen in $\mathrm{N}_{2}$. The leaves were removed in the time frame from 1:00 to $2: 30 \mathrm{pm}$. All samples were stored at $-80{ }^{\circ} \mathrm{C}$ until further analysis.

For the unbiased metabolite studies, for the 2 ecotypes and the 2 treatments (constitutive and herbivore-induced), 2 plants were taken at the time of caterpillar pupation and the experiment was repeated three times $(n=6$, total $n=24)$. For phytohormone analysis, plants were subjected to insect herbivory as outlined above, but total aerial tissue was removed and immediately frozen in $\mathrm{N}_{2}$ at $0,6,12$ and $24 \mathrm{hr}$ after continual herbivory. The experiment was repeated twice with 2 plants taken for each time point ( $n=4$, total $n=16)$.

Phytohormone Analysis Acidic hormones associated with the jasmonate burst, (cis-(+)-12-oxo-phytodienoic acid (OPDA), jasmonic acid (JA) and the biological form of jasmonic acid, (+)-7-iso-jasmonyl-L-isoleucine (JA-Ile)), as well as salicylic acid (SA) were analyzed at the Proteomics and Mass Spectrometry Facility at the Danforth Plant Centre (Missouri, USA). Plant tissues were lyophilized and finely ground. Deuterated internal standards of SA ( $\left.D^{5}-\mathrm{SA}\right)$, and JA ( $\mathrm{D}^{2}$-JA) were added to the plant samples that were then extracted in ice cold methanol:acetonitrile $(1: 1, \mathrm{v} / \mathrm{v})$. After centrifugation $(16,000 \mathrm{~g} \times 10 \mathrm{~min})$, supernatants were transferred, pellet extraction was repeated and supernatants pooled. The supernatant was evaporated using a speed-vacuum and the resulting residue dissolved in $30 \%$ methanol.

Phytohormone analysis was conducted by high performance liquid chromatography-tandem mass spectroscopy (HPLC-MS/MS). Separation was performed by reversephase HPLC using a $\mathrm{C}_{18}$ column (Onyx, $4.6 \mathrm{~mm} \times 100 \mathrm{~mm}$, Phenomenex) under a mobile gradient of $40 \%$ water containing $0.1 \%$ acetic acid (v/v) (Solvent $\mathrm{A}$ ) to $90 \%$ acetonitrile containing $0.1 \%$ acetic acid (v/v) (Solvent B) in 5 min with a flow rate of $1 \mathrm{ml} \mathrm{min}^{-1}$. Mass spectra were obtained by a 4000-QTRAP (AB Sciex) using the following parameters: negative mode ESI (TurbolonSpray), capillary voltage -4500 , nebulizer gas $\left(\mathrm{N}_{2}\right) 50$ arbitrary units (a.u.), heater gas 50 a.u., curtain gas 25 a.u., collision activation dissociation high, temperature $550{ }^{\circ} \mathrm{C}$. Compounds were identified based on multiple reaction monitoring transitions that were optimized for each phytohormone as well as the deuteriumlabelled standards (Pan et al. 2010). Phytohormone 
concentrations were determined from standard curves of known compounds.

Phytohormone levels were compared between F83005.5 and TN1.11 ecotypes at different times by 2-factor analysis of variance (2-factor ANOVA) using the statistical program SPSS (IBM SPSS statistics, ver. 23). If a significant difference was detected $(P \leq 0.05)$, then a 1 -factor ANOVA was conducted followed by a Tukey honest significant post hoc test to determine significant differences (Supplemental Table IIB).

Unbiased Metabolite Analysis Metabolites were analyzed according to Watson et al. (2015). Briefly, lyophilized foliar tissues were ground and extracted in $80 \%$ methanol for one hour at room temperature using slow, rotary shaking $(150 \mathrm{rpm})$. After centrifugation, the supernatant was filtered into a fresh vial and analyzed by ultrahigh performance liquid chromatography (Waters Acquity UPLC) coupled to a Waters Premier hybrid quadrupole time-of-flight (qTOF) mass spectrometer.

Separation was achieved by reverse-phase chromatography on a $\mathrm{C}_{18}$ column $(\mathrm{BEH}, 150 \times 2.1 \mathrm{~mm}$ i.d., $1.7 \mu \mathrm{m})$ maintained at $60{ }^{\circ} \mathrm{C}$ using a linear gradient from $5 \%$ acetonitrile in $0.1 \%(\mathrm{v} / \mathrm{v})$ aqueous acetic acid to $70 \%$ acetonitrile in $0.1 \%$ $(\mathrm{v} / \mathrm{v})$ aqueous acetic acid in $30 \mathrm{~min}$, at a flow rate of $0.56 \mathrm{ml} /$ $\mathrm{min}$. Metabolites were ionized by electrospray and detected by a qTOF mass spectroscopy operated in the negative mode. Tandem mass spectra data were acquired using a collision energy ramp from 55 to $110 \mathrm{eV}$. The mass spectrometry system was calibrated using sodium formate. Waters Markerlynx software was used to select and align peaks and perform quantification. Compounds were normalized relative to the internal standard (raffinose) and then to total ion abundance. Metabolites were identified by comparison against authentic standards or libraries based on accurate mass and retention time. Some metabolites were concentrated and further analyzed by nuclear magnetic resonance $\left({ }^{1} \mathrm{H},{ }^{13} \mathrm{C}\right.$, ROESY) as described below.

Metabolite levels (peak areas) were analyzed using MetaboAnalyst 3.0 (www.metaboanalyst.ca; Xia et al. 2015). Data were filtered using an interquantile range (IQR) and log-transformed and auto-scaled to normalize the data. Data was observed using Principal Component Analysis and heatmaps to understand global patterns. Levels of specific saponin metabolites were considered different between ecotypes or induced in response to herbivory if they met the criteria of being significantly different by 2 -factor ANOVA and having at least a one-fold (two times) difference in levels (Supplemental Tables III and IV).

Nuclear Magnetic Resonance (NMR) for Structural Determination To concentrate the specific compound for NMR structural determination, UPLC conditions were conducted as above except that separation was achieved using a linear gradient from $5 \%$ acetonitrile with $0.05 \%$ formic acid to $30 \%$ acetonitrile with $0.05 \%$ formic acid over $30 \mathrm{~min}$. The column eluent was divided in a ratio of 20:1 using a NMRMS bridge (Bruker) between a Spark-Holland Prospect II solid phase extraction (SPE) Waters Oasis HLB cartridges and qTOF-MS. Solid phase cartridges were conditioned with acetonitrile $(1 \mathrm{ml})$ and equilibrated with water containing $0.05 \%$ formic acid at $1 \mathrm{ml} / \mathrm{min}$. Peak trapping was controlled using the Bruker HyStar software: $1.75 \mathrm{ml} / \mathrm{min}$ water with $0.05 \%$ formic acid was added to the column eluent before trapping on the SPE cartridge. Fifteen to twenty $\times 8 \mu \mathrm{l}$ injections were used to obtain enough compound through repetitive SPE trapping. SPE cartridges were dried under $\mathrm{N}_{2}$. The extracted compounds were eluted from the SPE cartridges using methanol$d_{4}$. NMR spectra were obtained on a Bruker Avance III HD $600 \mathrm{MHz}$ spectrometer using a $1.7 \mathrm{~mm}$ TCI MicroCryoProbe at $298 \mathrm{~K}$. NMR data were obtained and processed using TopSpin 3.2 software. The spectra obtained in methanol- $d_{4}$ were referenced to residual solvent $\left({ }^{1} \mathrm{H}-3.31 \mathrm{ppm},{ }^{13} \mathrm{C}-\right.$ $49.15 \mathrm{ppm})$. The conditions used to obtain NMR data were as follows: one dimensional proton spectra (pulse sequence: WETDC (16 k) or zg30 (64 k); setup and performed with au_lc 1d) were recorded with the following relaxation delays: WETDC $-3 \mathrm{~s}, \mathrm{zg} 30-1 \mathrm{~s}$. NMR data were treated with an exponential function for line broadening of $0.3 \mathrm{~Hz}$ before Fourier transformation. Multiplicity edited HSQC, using the pulse sequence: hsqcedetgpsp.3, spectra were acquired using spectral widths of $9 \mathrm{ppm}$ for ${ }^{1} \mathrm{H}$ and $200 \mathrm{ppm}$ for ${ }^{13} \mathrm{C}$. For HSQC, $2 \mathrm{k}$ was taken for 96 or 128 data points with a relaxation delay of $1 \mathrm{~s}$. A 1D gradient selected ROESY (pulse sequence: selrogp) analysis which was recorded with a spinlock time of 400,000 $\mu \mathrm{s}$, a $2 \mathrm{~s}$ relaxation delay, and multiplied using an exponential function for a line-broadening of $1 \mathrm{~Hz}$ before Fourier transformation.

Statistical Analyses Statistical analyses have been outlined in each above section and were conducted using SPSS version 23 (SPSS Inc.). For the phytohormone analyses, the maximum normed residual Grubbs' test was used to identify and remove outliers (Grubbs 1969).

\section{Results}

\section{Identification of Most Deterrent (MD) and Least Deterrent (LD) Medicago truncatula Ecotypes to Caterpillar Herbivory}

In paired choice leaf tests between the six M. truncatula ecotypes that compared the amounts of detached trifoliate leaves eaten, ecotype A17 was the most deterrent followed by F83005.5, whereas DZA315.16 and TN1.11 had the highest biomass loss (Fig. 1a, Supplemental Table IA). The ranking of 
Fig. 1 Dual choice studies. a Detached trifoliate leaves. 4th instar Spodoptera exigua caterpillars were given the choice between detached trifoliate leaves of different Medicago truncatula ecotypes. Bars represent the mean biomass consumed (Fresh Weight, FW) of the two ecotypes \pm standard error $(n=24)$ (Supplemental Table IA). An asterix denotes the ecotype with significantly greater biomass loss determined by paired Student's ttest $(*: P<0.01$ **: $P<0.001)$. b Whole plants. Three 2nd instar S. exigua caterpillars were given the choice between whole plants of different $M$. truncatula ecotypes and allowed to feed until pupation. Bars represent the mean biomass loss (Fresh Weight, FW) of the two ecotypes \pm standard error $(n=10)$ (Supplemental Table IB). An asterix denotes the ecotype with significantly greater biomass loss determined by paired Student's t-test (*:

$P<0.01)$. In each experiment, to ensure random feeding, caterpillars were also given choices between either leaves or plants of the same ecotype (Supplemental Fig. 1A,B, Supplemental Table A,B)
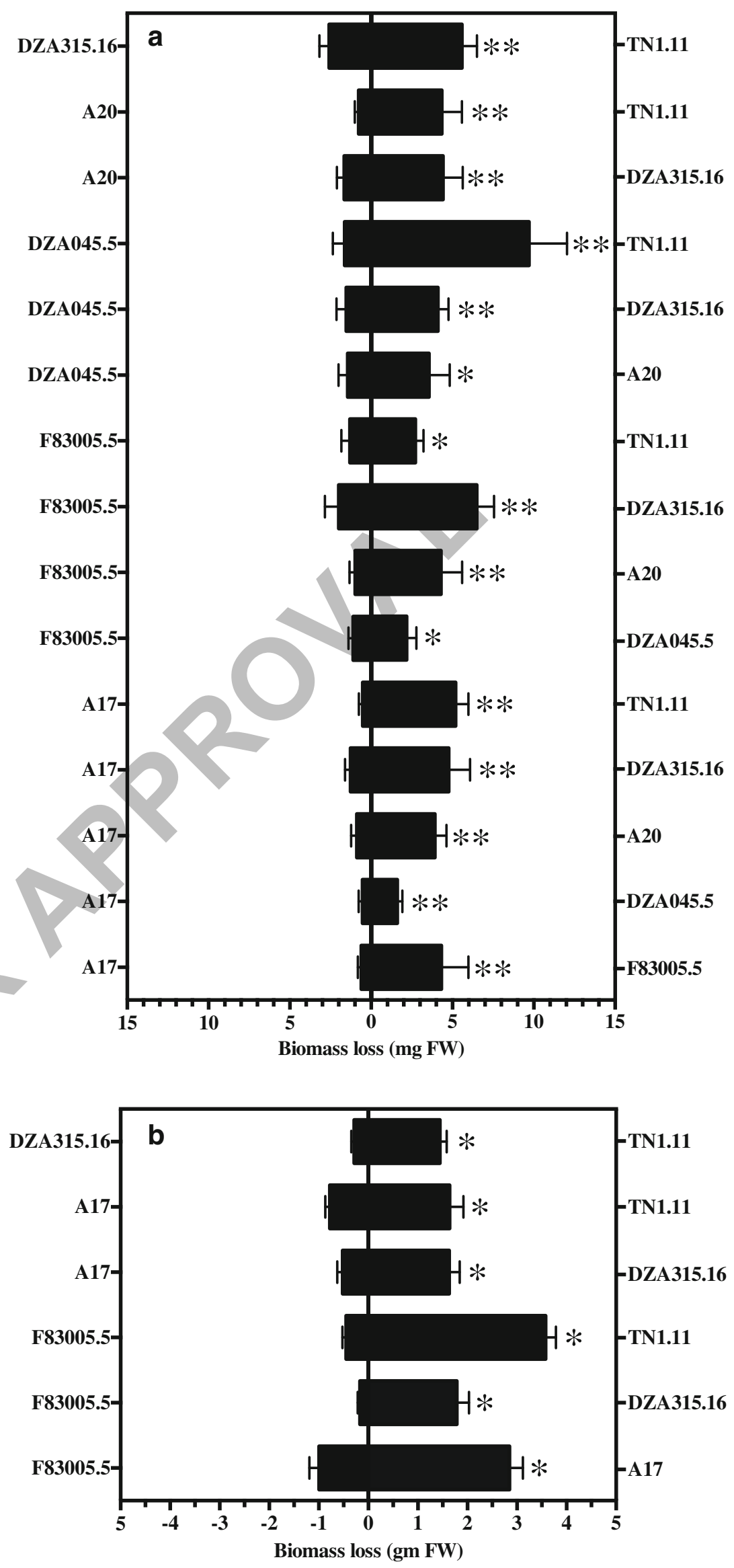
the different ecotypes in terms of biomass loss was A17 > F83005.5 > DZA045.5 > A20 > DZA315.6 > TN1.11. Caterpillars fed randomly when allowed to choose between sets of leaves from the same ecotype (Supplemental Fig. 1A, Supplemental Table IA).

Based on the leaf feeding study, the two most deterrent (MD), F823005.5 and A17, and two least deterrent (LD), DZA315.16 and TN1.11, ecotypes were compared in the whole plant choice tests (Fig. 1b). Of the four ecotypes tested, F83005.5 had the least biomass loss followed by A17 > DZA315.16, whereas TN1.11 was fed upon the most and was the most susceptible ecotype to caterpillar herbivory (Supplemental Table IB). These results differ slightly from the detached leaf choice assay where A17 was more resistant than F83005.5 and may reflect the transport of compounds from the root throughout the plant in response to herbivory. Though this phenomenon has not been reported to occur in M. trunctula, transport of root phytochemicals to aerial tissues in response to pathogen or insect attack has been observed in other plant species (Gaupels and Ghirardo 2013; Yazaki 2006). Caterpillars fed randomly when presented with two plants of the same ecotype (Supplemental Fig. 1B, Supplemental Table IB). Based on the two choice feeding studies, F83005.5 was chosen as the most deterrent (MD) and TN1.11 was chosen as the least deterrent (LD) ecotypes to caterpillar herbivory.

\section{Spodoptera exigua Performance}

There was no difference in caterpillar mortality when 2nd instar $S$. exigua caterpillars were restricted to either M. truncatula ecotypes TN1.11 (LD) or F83005.5 (MD) $(X(1)-3.64, P=0.55$, Supplemental Table IIA); approximately $70 \%$ of caterpillars survived until pupation when restricted to either ecotype. Plant ecotype did not affect development (number of larvae at the different instars on different days over the developmental course) (Day $4 X(2)=2.14, P=0.34$; Day $6 X(3)=3.20, P=0.36$; Day $8 X(1)=0.01 ; P=0.91$ ) (Fig. 2a, Supplemental Table IIA) or pupal biomass $(P=0.56)$ (Fig. $2 \mathrm{~b}$, Supplemental Table IIA).

\section{Medicago truncatula Defense-Related Phytohormones}

As expected, a rapid and strong jasmonate burst was observed in response to caterpillar herbivory (Fig. 3, Supplemental Table IIB). After $24 \mathrm{hr}$ of continuous herbivory, this was manifested by a six- to thirteen-fold and an eighteen- to fifty-fold increase in JA and JA-Ile compared to constitutive levels (Fig. $3 \mathrm{~b}, \mathrm{c})$. In contrast, levels of the jasmonic acid biosynthetic intermediate and defensive compound 12-oxo-phytodienoic acid were not affected by insect herbivory (Fig. 3) (Dave and Graham 2012; Shabab et al. 2014). Salicylic acid levels also increased in response to caterpillar herbivory with a
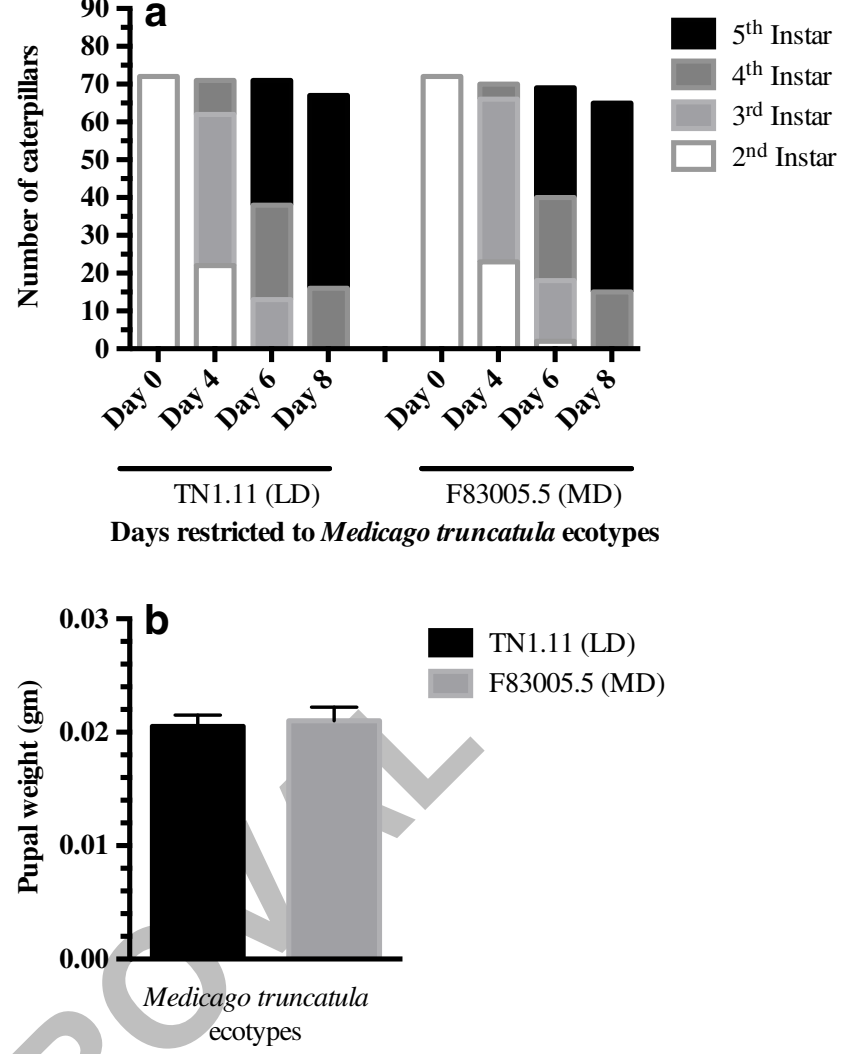

Fig. 2 Spodoptera exigua performance on Medicago truncatula ecotypes. Caterpillar development (a) and pupal biomass (b) were measured on larvae restricted to either M. truncatula ecotypes, TN1.11 (least deterrent, LD) or F83005.5 (most deterrent, MD). The experiment was repeated three times with 24 caterpillars ( 3 per plant) on each ecotype followed each time (total $n=72$ ). Caterpillar development was statistically analyzed by Pearson's Chi-Square and pupal mass by Student's t-test (Supplemental Table IIA)

significant increase noted after $24 \mathrm{hr}$, compared to constitutive levels (Fig. 3d). Differences in phytohormone levels between the two ecotypes tested, F83005.5 and TN1.11, were not observed (Fig. 3a-d). In addition, activity of jasmonatedependent defenses, such as trypsin inhibitor and polyphenol oxidase (Bosch et al. 2014; Paudel and Bede 2015), did not show an ecotype-specific difference (Supplemental Fig. 2, Supplemental Table IIC).

\section{Medicago truncatula Metabolites}

Six hundred and forty-seven metabolites were observed by UPLC-qTOF MS (Supplemental Table III). Principal component analysis (PCA) showed that the metabolite profile was more reflective of ecotype than treatment (Fig. 4a); approximately $45 \%$ of observed compounds were differently expressed between the two ecotypes.

Saponins are notoriously difficult to identify because of the positioning of the glycoside moieties (Khakimov et al. 2016); 

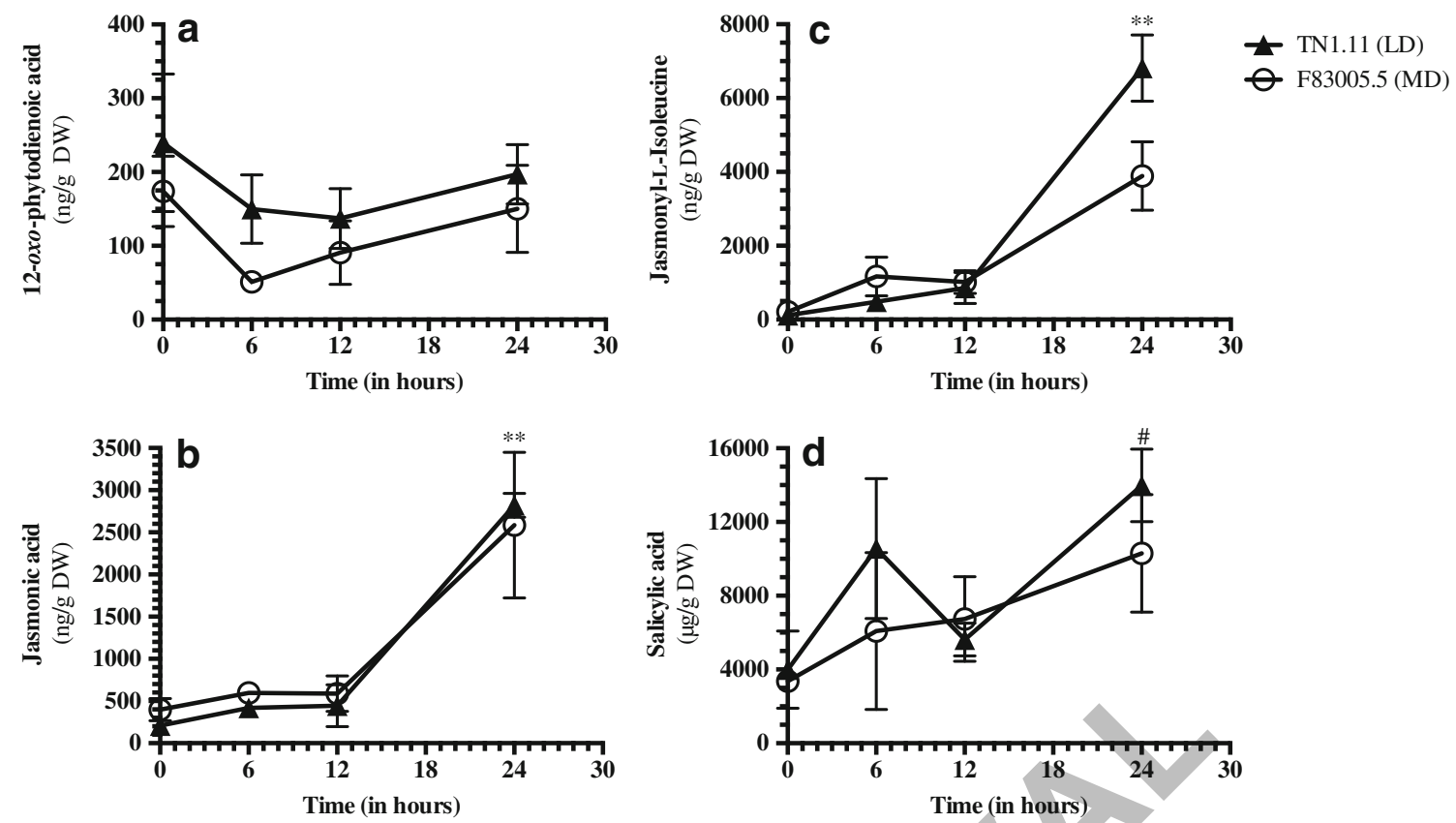

Fig. 3 Foliar phytohormone dynamics in Medicago truncatula ecotypes in response to caterpillar herbivory. Leaf phytohormone levels in the first $24 \mathrm{hr}$ after continuous herbivory by three $2 \mathrm{nd}$ instar Spodoptera exigua caterpillars were compared in two M. truncatula ecotypes, TN1.11 (least deterrent, LD, - $\mathbf{-}$ ) and F83005.5 (most deterrent, MD, $\bullet$ ). Foliar phytohormones: (a) 12-oxo-phytodienoic acid (OPDA), (b) jasmonic

however, accurate identification of the aglycone base can usually be determined. In this study, metabolites are positively or putatively annotated as saponins (Supplemental Table IV AC); positive identifications were made by NMR, tandem MS or comparison to an authentic sample. Putative identifications were based on $\mathrm{m} / \mathrm{z}$ ( $\pm 6 \mathrm{ppm})$, retention time, fragmentation math and scientific literature. Other metabolites suspected to be saponins based on their $\mathrm{m} / \mathrm{z}$ and retention time are also listed in Supplemental Table IV (D-F). Of the thirty seven metabolites positively or putatively annotated as saponins (Supplemental Table IV), sixteen of these show ecotypespecific differences, based on ANOVA and one-fold or greater change in compound levels between ecotypes (Fig. 4b, c). All but one of the eight medicagenic acid conjugates are significantly higher in more deterrent plants than in the more susceptible line. Four zanhic acid conjugates are also higher in the more deterrent ecotype F83005.5, compared to one zanhic acid derivative in TN1.11.

\section{Discussion and Conclusions}

Six M. truncatula ecotypes were compared for their resistance to $S$. exigua caterpillar herbivory. Through leaf and whole plant choice studies, the more deterrent F83005.5 and less deterrent TN1.11 ecotypes were identified (Fig. 1a, b). Both

acid (c) (+)-7-jasmonoyl-L-isoleucine (d) salicylic acid. Statistical differences were determined by 2 -factor analysis of variance (Supplemental Table IIB). \# indicates a significant difference compared to constitutive levels, $* *$ indicates a significant difference compared to previous time points $(0,6,12 \mathrm{hr})$

ecotypes show a strong, robust increase in the defensive phytohormones salicylic acid and jasmonates in response to herbivory (Fig. 4b-d). Ogawa et al. (2010) also observed a wound-induced increase in foliar total salicylic acid levels after wounding of Arabidopsis thaliana plants with carborundum. As seen in previous studies (Paudel and Bede 2015), herbivory induces a strong jasmonate burst of jasmonate and jasmonyl-L-isoleucine but not OPDA within $24 \mathrm{hr}$ of continuous herbivory (Fig. 3a-c). This jasmonate burst is the phytohormone signal leading to induced plant defenses targeted against caterpillar herbivory (Wasternack and Hause 2013). However, in the present study, a difference in phytohormone levels between the two ecotypes is not observed (Fig. 3).

The performance of caterpillars restricted to the different $M$. truncatula ecotypes were compared since longer developmental times increase caterpillar exposure to natural enemies, as well as may negatively affect the number of reproductive cycles during a season. As well, S. exigua pupal mass is highly correlated with insect fecundity (Greenberg et al. 2001). When caterpillars were restricted to these ecotypes, there is no apparent difference in insect performance (Fig. 2, Supplemental Table 1IA); M. truncatula ecotype did not effect caterpillar development, pupal biomass or mortality. Together, these results argue against an ecotype-specific difference in plant noxious specialized metabolites (antibiosis resistance mechanism), but favour an antifeedant deterrent mechanism. 
a Unbiased metabolomics i. Principal Component Analysis

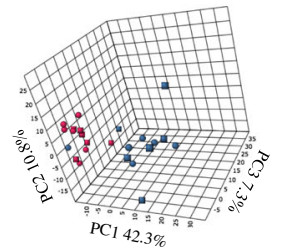

- TN1.11 (LD) constitutive - F83005.5 (MD) constitutive a TN1.11 (LD) caterpillar herbivory - F83005.5 (MD) caterpillar herbivory ii. Heatmap

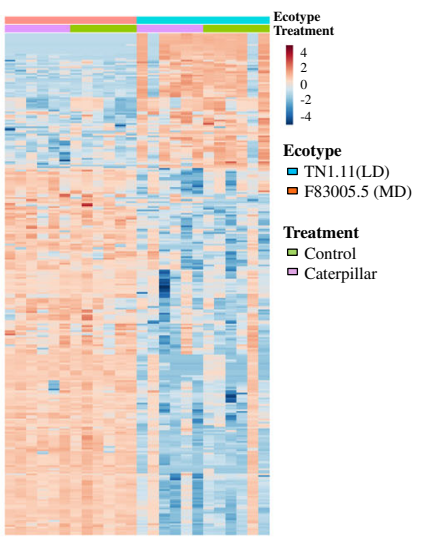

b
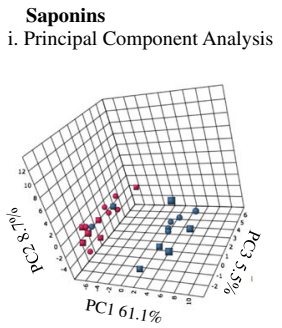

- TN1.11 (LD) constitutive - F83005.5 (MD) constitutive a TN1.11 (LD) caterpillar herbivory - F83005.5 (MD) caterpillar herbivory

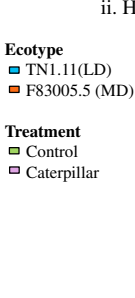

ii. Heatmap

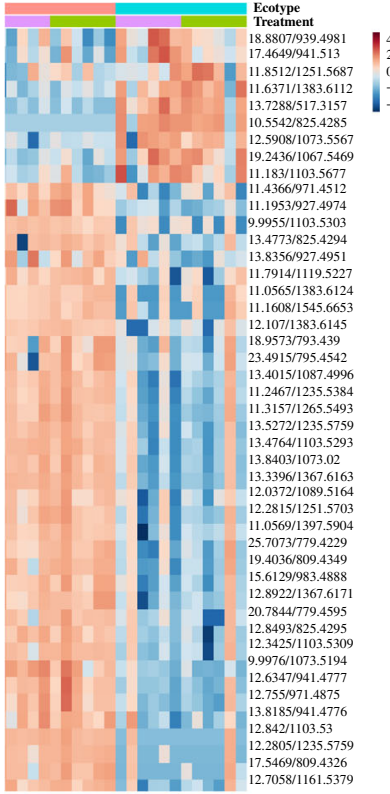

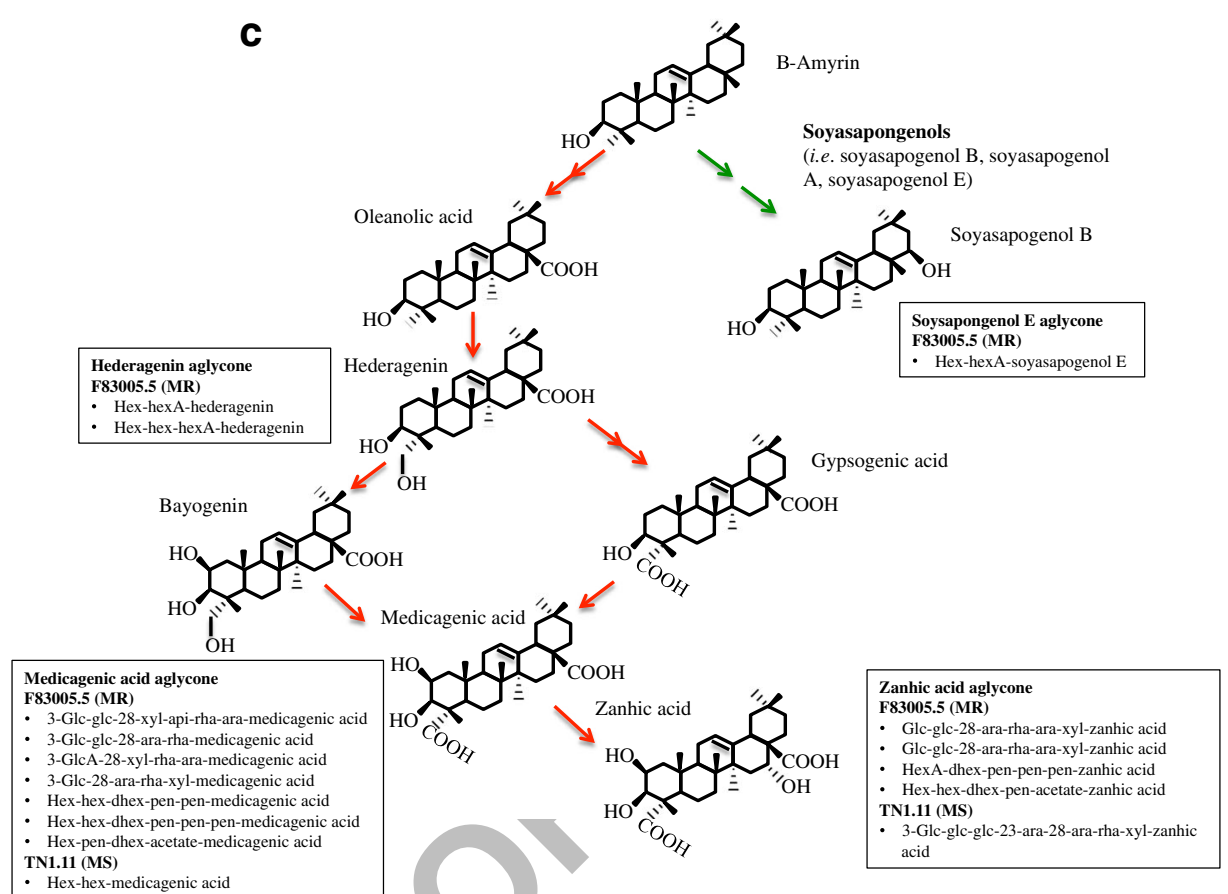

Fig. 4 Metabolite profile of Medicago truncatula ecotypes in response to caterpillar herbivory. Foliar metabolite levels were compared in in two M. truncatula ecotypes, TN1.11 (least deterrent, LD) and F83005.5 (most deterrent, MD), after two weeks of continuous Spodoptera exigua caterpillar herbivory. Unbiased metabolites (a) and saponin (b) levels are represented by i) Principal Component Analysis and ii) Heat Maps. Heat maps only represent compounds that are significantly different between ecotypes or treatments ( 2 -factor ANOVA, $P \leq 0.05$ ) (Supplemental Tables III, IV). For both unbiased metabolites (a) and saponins (b), PCA analyses shows that metabolite profile is more distinct according to ecotype (red $=\mathrm{F} 83005.5$, blue $=\mathrm{TN1}$.11) compared to treatment $($ constitutive $=$ circle, , aterpillar induced $=$ square $)$. This pattern is also observed in the heat map where ecotype differences are more

Unbiased metabolomics identified quantitative and qualitative differences in saponin content between the two ecotypes (Fig. 4b, c, Supplemental Table IV); F83005.5 has more and higher constitutive and induced levels of oleanolic-type pronounced than treatment (red represents higher compound levels and the blue represents lower compound levels). On the saponin heatmap, the numbers beside the heatmap indicate the compound retention time and $\mathrm{m} /$ z ratio (Supplemental Table IV). c Saponin biosynthetic pathway. After $\beta$-amyrin, there is a bifurcation of saponin biosynthesis into the oleanolic(i.e. hederagenin, medicagenic acid, zanhic acid) or soyasapogenolderived saponin classes. The inset boxes by the different aglycone types identify saponins that were increased in either the TN1.11 (LD) or F83005.5 (MD) ecotypes. The retention time and $\mathrm{m} / \mathrm{z}$ ratio are given in Supplemental Table IV. Abbreviations: Api: apiofuranose, Ara: arabinose, Dhex: deoxyhexose, Glc: glucose, GlcA: galacturonic acid, Hex: hexose, HexA: uronic acid, Pen: pentose, Rha: rhamnose, $X y l$ : xylose

saponins than the caterpillar-susceptible TN1.11 ecotype. These oleanoic-type saponins, especially the medicagenic acid conjugates, are likely to play an important role in plant resistance (Faizal and Geelen 2013). Previous studies have 
shown that the saponin precursor $\beta$-amyrin and soyasapogenin B had little effect on the feeding behaviour of the Spilosoma oblique caterpillars (Jain and Tripathi 1991). In contrast, Agrell et al. (2003) observed that 4th instar Spodoptera littoralis caterpillars preferred undamaged plants of Medicago sativa, alfalfa, a close relative to M. truncatula, over wounded plants that had higher levels of medicagenic acid- and soyasaponin-type saponins. Caterpillars restricted to the damaged alfalfa plants did not show alterations in development time but did have reduced pupa biomass (Agrell et al. 2003). Together with our results, this argues for the role of oleanolic-derived saponins as antifeedants since in our study, insects showed a preference for the M. truncatula ecotype with lower hederagenin-, medicagenin- and zhanic acidderived saponins even though restriction to the different ecotypes does not affect caterpillar performance (Figs. 1, 2, 4). Antifeedants often act by stimulating deterrent sensory cells or by interfering with positive feeding signals rather than having a direct toxic effect, leading to a behavioural antixenosis mechanism of resistance (Isman 2002; Koul 2008).

Though we cannot exclude the possibility that deterrencerelated resistance is due to other specialized metabolites not examined in this study, the established role of oleanolicderived medicagenic-type saponins as potent antifeedants provides compelling evidence that the strong presence of oleanolic-type saponins in M. truncatula F83005.5 ecotype may be, in part, responsible for deterrence; however, this must be tested through further insect physiological studies to identify sensilla-specific responses to these compounds. Also, the identification of two M. truncatula ecotypes that produce substantially different saponin chemotypes will allow investigation into the regulation of saponin biosynthesis that leads to the bifurcation between oleanolic- and soyasapogenol-derived saponins. Finally, the production of antifeedants in crop legumes is an interesting avenue to be explored in sustainable integrated pest management practices.

Acknowledgements We thank Drs. J. Howieson and J. Terpolilli (Murdoch University) for the Ensifer medicae WSM419 culture. We thank Jingyuan Ji, Joshua Lee and Yifan Liu for assistance with caterpillar herbivory experiments. We thank the anonymous reviewers of a previous version of this manuscript for their insightful comments. Phytohormone analysis was conducted at the Proteomics \& Mass Spectrometry Facility, Danforth Plant Science Center that is supported by a National Science Foundation grant \#DBI-1427621 used to purchase a QTRAP LC-MS/ MS. This research was funded through a Natural Sciences and Engineering Research Council of Canada grant to JCB.

\section{References}

Adel MM, Sammour EA (2012) Effect of sub-lethal dose of natural compound of Medicago sativa (L., Leguminaceae) on the hind gut and fatbody of Spodoptera littoralis (Lepidoptera, Noctuidae). J Appl Sci Res 8:1398-1408
Adel MM, Sehnal F, Jurzysta M (2000) Effects of alfalfa saponins on the moth Spodoptera littoralis. J Chem Ecol 26:1065-1078

Agrell J, Oleszek W, Stochmal A, Olsen M, Anderson P (2003) Herbivore-induced responses in alfalfa (Medicago sativa). J Chem Ecol 29:303-320

Ben C, Toueni M, Montanari S, Tardin MC, Fervel M, Negahi A, SaintPierre L, Mathieu G, Gras MC, Noël D, Prospéri JM, Pilet-Nayel ML, Baranger A, Huguet T, Julier B, Rickauer M, Gentzbittel L (2013a) Natural diversity in the model legume Medicago truncatula allows identifying distinct genetic mechanisms conferring partial resistance to Verticillium wilt. J Exp Bot 64:317-332

Ben C, Debellé F, Berges H, Bellec A, Jardinaud MF, Anson P, Huguet T, Gentzbittel L, Vailleau F (2013b) MtQRRS1, an R-locus required for Medicago truncatula quantitative resistance to Ralstonia solanacearum. New Phytol 199:758-772

Bosch M, Berger S, Schaller A, Stintzi A (2014) Jasmonate-dependent induction of polyphenol oxidase activity in tomato foliage is important for defense against Spodoptera exigua but not against Manduca sexta. BMC Plant Biol 14:257

Choi HK, Kim D, Uhm T, Limpens E, Lim H, Mun JH, Kalo P, Penmetsa RV, Seres A, Kulikova O (2004) A sequence-based genetic map of Medicago truncatula and comparison of marker colinearity with M. sativa. Genetics 166:1463-1502

Da Silva P, Eyraud V, Carre-Pierrat M, Sivignon C, Rahioui I, Royer C, Gressent F (2012) High toxicity and specificity of the saponin 3GlcA-28-AraRhaXyl-medicagenate, from Medicago truncatula seeds, for Sitophilus oryzae. BMC Chem Biol 12:3

Dave A, Graham IA (2012) Oxylipin signaling: a distinct role for the jasmonic acid precursor cis-(+)-12-oxo-phytodienoic acid (cisOPDA). Front Plant Sci 3:42

De Geyter E, Lamber E, Geelen D, Smagghe G (2007) Novel advances with plant saponins as natural insecticides to control pest insects. Pest Technol 1:96-105

De Geyter E, Swevers L, Soin T, Geelen D, Smagghe G (2012) Saponins do not effect the ecdysteroid receptor complex but cause membrane permeation in insect cell cultures. J Insect Physiol 58:18-23

Djébali N, Jauneau A, Ameline-Torregrosa C, Chardon F, Jaulneau V, Mathé C, Bottin A, Cazaux M, Pilet-Nayel ML, Baranger A (2009) Partial resistance of Medicago truncatula to Aphanomyces euteiches is associated with protection of the root stele and is controlled by a major QTL rich in proteasome-related genes. Mol PlantMicrobe Interact 22:1043-1055

Faizal A, Geelen D (2013) Saponins and their role in biological processes in plants. Phytochem Rev 12:877-893

Gaige AR, Doerksen T, Shui B (2012) Medicago truncatula ecotypes A17 and R108 show variation in jasmonic acid/ethylene induced resistance to Macrophomina phaseolina. Can J Plant Pathol 34: 98-103

Gao LL, Klingler JP, Anderson JP, Edwards OR, Singh KB (2008) Characterization of pea aphid resistance in Medicago truncatula. Plant Physiol 146:996-1009

Garcia, J, Barker DG, Journet EP (2006) Seed storage and germination. In: The Medicago truncatula handbook. Mathesius U, Journet EP, Sumner LW (eds) ISBN 0-9754303-1-9 (https://www.noble.org/medicago-handbook)

Gaupels F, Ghirardo A (2013) The extrafascicular phloem is made for fighting. Front Plant Sci 4:1-4

Gentzbittel L, Andersen SU, Ben C, Rickauer M, Stougaard J, Young ND (2015) Naturally occurring diversity helps to reveal genes of adaptive importance in legumes. Front Plant Sci 6:269

Gholami A, De Geyter N, Pollier J, Goormachtic S, Goossens A (2014) Natural product biosynthesis in Medicago species. Nat Prod Rep 31: $356-380$

Goławska S (2007) Deterrence and toxicity of plant saponins for the tea aphid, Acyrthosiphon pisum Harris. J Chem Ecol 33:1598-1606 
Goławska S, Łukasik I, Wójcicka A, Sytykiewicz H (2012) Relationship between saponin content in alfalfa and aphid development. Acta Biol Cracov 2:1-8

Greenberg S, Sappington T, Legaspi B, Liu T, Setamou M (2001) Feeding and life history of Spodoptera exigua (Lepidoptera: Noctuidae) on different host plants. Ann Entomol Soc Am 94:566-575

Grubbs FE (1969) Procedures for detection outlying observations in samples. Technometrics 11:1-21

Guo SM, Kamphuis LG, Gao LL, Klingler JP, Lichtenzveig J, Edwards O, Singh KB (2012) Identification of distinct quantitative trait loci associated with defence against the closely related aphids Acyrthosiphon pisum and A. kondoi in Medicago truncatula. J Exp Bot 63:3913-3922

Horber E, Leath KT, Berrang B, Marcarian V, Hanson CH (1974) Biological activities of saponin components from Dupuits and Lahontan alfalfa. Entomol Exp Appl 17:410-424

Huhman DV, Sumner LW (2002) Metabolic profiling of saponins in Medicago sativa and Medicago truncatula using HPLC coupled to an electrospray ion-trap mass spectrometer. Phytochemistry 59:347-360

Huhman DV, Berhow MA, Sumner LW (2005) Quantification of saponins in aerial and subterranean tissues of Medicago truncatula. J Agric Food Chem 53:1914-1920

Isman M (2002) Insect antifeedants. Pestic Outlook 13:152-157

Jain DC, Tripathi AK (1991) Insect feeding-deterrent activity of some saponin glycosides. Phytother Res 5:139-141

Kapusta I, Janda B, Stochmal A, Oleszek W (2005) Determination of saponins in aerial parts of barrel medic (Medicago truncatula) by liquid chromatography-electrospray ionization/mass spectrometry. $\mathrm{J}$ Agric Food Chem 53:7654-7660

Khakimov B, Tseng LH, Godejohann M, Bak S, Engelsen SB (2016) Screening for triterpenoid saponins in plant using hyphenated analytical platforms. Molecules 21:1614

Koul O (2008) Phytochemicals and insect control: an antifeedant approach. Crit Rev Plant Sci 27:1-24

Lazrek F, Roussel V, Ronfort J, Cardinet G, Chardon F, Aouani ME, Huguet $T$ (2009) The use of neutral and non-neutral SSRs to analyse the genetic structure of a Tunisian collection of Medicago truncatula lines and to reveal associations with eco-environmental variables. Genetica 135:391-402

Maxmen A (2013) Crop pests: under attack. Nature 501:S15-S17

Mithöfer A, Boland W (2012) Plant defense against herbiyores: chemical aspects. Annu Rev Plant Biol 63:431-450

Moses T, Papadopoulou KK, Osbourn A (2014) Metabolic and functional diversity of saponins, biosynthetic intermediates and semi-synthetic derivatives. Crit Rev Biochem Mol Biol 49:439-462

Negahi A, Ben C, Gentzbittel L, Maury P, Nabipour AR, Ebrahimi A, Sarrafi A, Richauer M (2013) Quantitative trait loci associated with resistance to a potato isolate of Verticillium albo-atrum in Medicago truncatula. Plant Pathol 63:308-315

Nozzolillo C, Arnason JT, Campos F, Donskov N, Jurzysta M (1997) Alfalfa leaf saponins and insect resistance. J Chem Ecol 23:995-1002

Ogawa T, Ara T, Aoki K, Suzuki H, Shibata D (2010) Transient increase in salicylic acid and its glucose conjugates after wounding in Arabidopsis leaves. Plant Biotechnol 27:205-209

Pan X, Welti R, Wang X (2010) Quantitative analysis of major plant hormones in crude plant extracts by high-performance liquid chromatography-mass spectrometry. Nat Protoc 5:986-992

Paudel JR, Bede JC (2015) Ethylene signaling modulates herbivoreinduced defense responses in the model legume Medicago trunctula. Mol Plant-Microbe Interact 28:569-579

Podolak I, Galanty A, Sobolewska D (2010) Saponins as cytotoxic agents: a review. Phytochem Rev 9:425-474

Rahoui S, Ben C, Chaoui A, Martinez Y, Yamchi A, Richauer M, Gentzbittel L, El Ferjani E (2014) Oxidative injury and antioxidant genes regulation in cadmium-exposed radicales of six contrasted Medicago truncatula genotypes. Environ Sci Pollut Res Int 21: 8070-8083

Rahoui S, Martinez Y, Sakouhi L, Ben C, Rickauer M, El Ferjani E, Gentzbittel L, Chaoui A (2016) Cadmiuminduced changes in antioxidative systems and differentiation in roots of contrasted Medicago truncatula lines. Protoplasma. doi:10.1007/500709-016-0968-9

Rose RJ (2008) Medicago truncatula as a model for understanding plant interactions with other organisms, plant development and stress biology: past, present and future. Funct Plant Biol 35:253-264

Rubiales D, Fondevilla S, Chen W, Gentzbittel L, Higgins TJV, Castillejo MA, Singh KB, Rispail N (2015) Achievements and challenges in legume breeding for pest and disease resistance. Crit Rev Plant Sci $34: 1-42$

Scholes DR, Siddappaji MH, Paige KN (2013) The genetic basis of overcompensation in plants: a synthesis. Int J Mod Bot 3:34-42

Shabab M, Khan SA, Vogel H, Heckel DG, Boland W (2014) OPDA isomerase GST16 is involved in phytohormone detoxification and insect development. FEBS J 281:2769-2783

Smith CM, Clement SL (2012) Molecular bases of plant resistance to arthropods. Annu Rev Entomol 57:309-328

Stewart SA, Hodge S, Ismail N, Mansfield JW, Feys BJ, Prospéri JM, Huguet T, Ben C, Gentzbittel L, Powell G (2009) The RAP1 gene confers effective, race-specific resistance to the pea aphid in Medicago truncatula independent of the hypersensitive reaction. Mol Plant-Microbe Interact 22:1645-1655

Szczepanik M, Krystkowiak K, Jurzysta M, Baiły Z (2001) Biological activity of saponins from alfalfa tops and roots against Colorado potato beetle larvae. Acta Agrobot 54:34-45

Tang H, Krishnakumar V, Bidwell S, Rosen B, Chan A, Zhou S, Gentzbittel L, Childs KL, Yandell M, Gundlach H, Mayer KFX, Schwartz DC, Town CD (2014) An improved genome release (version Mt4.0) for the model legume Medicago trunctula. BMC Genomics 15:312

Tava A, Odoardi M (1996) Saponins from Medicago spp.: chemical characterization and biological activity against insects. In: Waller GR, Yamasaki K (eds) Saponins used in food and Agriculture. Springer Netherlands, New York, pp 97-109

Taylor WG, Fields PG, Sutherland DH (2004) Insectical components from field pea extracts: Soyasaponins and lysolectins. J Agric Food Chem 52:7484-7490

Terpolili JJ, O'Hara GW, Tiwari RP, Dilworth MJ, Howieson JG (2008) The model legume Medicago truncatula A17 is poorly matched for $\mathrm{N}_{2}$ fixation with the sequenced microsymbiont Sinorhizobium meliloti 1021. New Phytol 179:62-66

Tivoli B, Baranger A, Sivasithamparam K, Barbett MJ (2006) Annual Medicago: from a model crop challenged by a spectrum of nectrotrophic pathogens to a model plant to explore the nature of disease resistance. Ann Bot 98:1117-1128

Trumble JT, Kolodny-Hirsch DM, Ting IP (1993) Plant compensation for arthropod herbivory. Annu Rev Entomol 38:93-119

Wasternack C, Hause B (2013) Jasmonates: biosynthesis, perception, signal transduction and action in plant stress responses, growth and development. An update to the 2007 review in Annals of Botany. Ann Bot 111:1021-2058

Watson BS, Bedair MF, Urbanczyk-Wochniak E, Huhman DV, Yang DS, Allen SN, Li W, Tang Y, Sumner LW (2015) Integrated metabolomics and transcriptomics reveal enhanced specialized metabolism in Medicago truncatula root border cells. Plant Physiol 167:1699-1716

Xia J, Sinelnikov I, Han B, Wishart DS (2015) MetaboAnalyst 3.0 making metabolomics more meaningful. Nucleic Acids Res 43: W251-W257

Yazaki K (2006) ABC transporters involved in the transport of plant secondary metabolites. FEBS Lett 580:1183-1191 
Young ND, Bharti AK (2012) Genome-enabled insights into legume biology. Annu Rev Plant Biol 63:283-305

Young ND, Udvardi M (2009) Translating Medicago truncatula genomics to crop plants. Curr Opin Plant Biol 12:193-201

Young ND, Cannon SB, Sato S, Kim D, Cook DR, Town CD, Roe BA, Tabata $S$ (2005) Sequencing the genespaces of Medicago truncatula and Lotus japonicus. Plant Physiol 137:1174-1181
Zahaf O, Blanchet S, De Zélicourt A, Alunni B, Plet J, Laffont C, De Lorenzo L, Imbeaud S, Ichanté JL, Diet A (2012) Comparative transcriptomic analysis of salt adaptation in roots of contrasting Medicago truncatula genotypes. Mol Plant 5:1068-1081 